\title{
Has the mammary gland a protective mechanism against overexposure to triiodothyronine during the peripartum period? The prolactin pulse down-regulates mammary type I deiodinase responsiveness to norepinephrine
}

\author{
B Anguiano, R Rojas-Huidobro, G Delgado and C Aceves \\ Instituto de Neurobiología, UNAM-Juriquilla, Querétaro, México 76230 \\ (Requests for offprints should be addressed to C Aceves Velasco, Instituto de Neurobiología, UNAM-Juriquilla, Km 15 Carretera Qro-SLP, Juriquilla, \\ Qro, 76230, México 76230; caracev@servidor.unam.mx)
}

\begin{abstract}
Peripartum is a crucial period for mammary gland final differentiation and the onset of lactation. Although the 'trigger' for lactogenesis depends on several hormones, a key factor is the peripartum prolactin (PRL) pulse whose deletion results in a failure to initiate milk production. Other hormones having a critical role during this period but exerting a contrary effect are the thyronines. A transitory hypothyroidism occurs at peripartum in serum and several other extrathyroidal tissues, whereas the induction of hyperthyroidism during late pregnancy is associated with the absence of lactation after delivery. We analyzed the mammary gland during pregnancy and lactation for: (a) the type and amount of thyroid receptors (TRs), (b) the local triiodothyronine (T3) generation catalyzed by type I deiodinase (Dio1), (c) the Dio1 response to norepinephrine (NE) and (d) the effect on Dio1 and
\end{abstract}

TRs of blocking the PRL pulse at peripartum. Our data showed that during pregnancy the mammary gland contains Dio1 in low amounts associated with the highest expression of TR $\alpha 1$; whereas during lactation the gland shows high levels of both Dio1 and TR $\beta 1$. However, at peripartum, both TRs and Dio1 decrease, and Dio1 becomes refractory to NE. This refractoriness disappears when the PRL pulse is blocked by the dopamine agonist bromocriptine. This blockade is also accompanied by a significant decrease in cyclin D1 expression. Our data suggested that the peripartum PRL pulse is part of a protective mechanism against precocious differentiation and/or premature involution of the alveolar epithelium due to T3 overexposure.

Journal of Endocrinology (2004) 183, 267-277

\section{Introduction}

Thyroid hormones (TH) display a wide variety of biological effects in vertebrates, but their most remarkable actions can be found in the regulation of development and cell differentiation (Anderson et al. 2000). The sympathetic nervous system (SNS) and prolactin (PRL) have been frequently implicated as synergistic and antagonistic influences upon the effects of $\mathrm{TH}$ and viceversa. $\mathrm{TH}$ antagonizes PRL action by inhibiting the synthesis of the signal transducer and activator of transcription 5 (Stat5), which is a key component of the PRL signaling pathway (Favre-Young et al. 2000). In the case of the SNS, THs are known to regulate sympathetic action by modulating the expression of $\beta$-adrenergic receptors (Mayollan \& Horowitz 2002). The actions of the SNS and PRL upon $\mathrm{TH}$ are less clear, but in some tissues they may influence its peripheral biotransformation. The SNS increases the enzymatic deiodination of the prohormone thyroxine (T4) to the active hormone tri-iodothyronine (T3) in brown adipose tissue, heart and lactating mammary gland (Silva \& Larsen 1983, Aceves \& Rojas-Huidobro 2001); whereas PRL seems to modulate this activity only in the lactating mammary gland (Aceves et al. 1999a). We have previously reported that the lactating rat mammary gland exhibits type 1 deiodinase (Dio1) which catalyzes the T4 to T3 conversion. This enzyme can be detected beginning in mid-pregnancy, and its synthesis increases considerably $48 \mathrm{~h}$ postpartum. In mid-lactation, expression of mammary Dio1 (MDio1) is at its peak and may locally provide significant amounts of $\mathrm{T} 3$ and iodine to the alveolar epithelium (Aceves et al. 1995). At this time, MDio1 synthesis is regulated by the suckling stimulus, in which both $\beta$ adrenergic innervation and PRL have primary roles (Aceves et al. 1999a). In contrast, during the peripartum period, mothers exhibit a 'transitory hypothyroidism' characterized by a decrease in T4 and T3 contents in several extrathyroidal tissues including plasma, liver, kidney, lung, 
Table 1 Oligonucleotides used in the RT-PCR amplification

\begin{tabular}{|c|c|c|c|}
\hline & $\begin{array}{l}\text { Size } \\
(b p)\end{array}$ & Sequence & Type \\
\hline Dio1 & 250 & $\begin{array}{l}\text { 377-GCACСТGАССТТСАТТТСТ } \\
\text { 627-СTGGСТGСТСТGGTTCTG }\end{array}$ & $\begin{array}{l}\text { sense } \\
\text { antisense }\end{array}$ \\
\hline $\mathrm{TR} \alpha 1$ & 254 & $\begin{array}{l}\text { 1736-GGG CGA CAA ATG AAC TTG CT } \\
\text { 1990-TAT TTG GGG AAG TAG AGA CCT }\end{array}$ & $\begin{array}{l}\text { sense } \\
\text { antisense }\end{array}$ \\
\hline TR $\beta 1$ & 320 & $\begin{array}{l}\text { 132-CCG TGG TIT CCC TCT CCT TA } \\
452-\text { AAT ATA GAG CTC GCC CAA GT }\end{array}$ & $\begin{array}{l}\text { sense } \\
\text { antisense }\end{array}$ \\
\hline S14 & 451 & $\begin{array}{l}\text { 2-ATGCAAGTGCTAACGAAACGCTACCC } \\
\text { 453-CTACAGGACCTGCCCCGTCATTCC }\end{array}$ & $\begin{array}{l}\text { sense } \\
\text { antisense }\end{array}$ \\
\hline Cyclin D1 & 315 & $\begin{array}{l}\text { 267-GTC CAG AGG GAG ATT GTG CC } \\
582-G C G \text { GCC CAG GTT CCA TTT GAG }\end{array}$ & $\begin{array}{l}\text { sense } \\
\text { antisense }\end{array}$ \\
\hline Cyc & 520 & $\begin{array}{l}\text { 7-AGA CGC CGC TGT CTC TTT TCG } \\
527-C C A \text { CAC AGT CGG AGA TGG TGA TC }\end{array}$ & $\begin{array}{l}\text { sense } \\
\text { antisense }\end{array}$ \\
\hline
\end{tabular}

heart and skeletal muscle. This physiological hypothyroidism has been interpreted as a homeorhetic mechanism aimed at channeling energy to fetal growth (Calvo et al. 1990). This local hypothyroidism may also be related to the antagonism between TH and PRL in the mammary gland. During the peripartum period there is rapid growth of the lobulo-alveolar complex, which is associated with the high and sustained PRL secretion that occurs simultaneously (Schams et al. 1972, Akers et al. 1981, Akers 1985). Several studies have shown that this PRL pulse is also essential for the initiation of lactation. Treatment at the end of pregnancy with the dopamine agonist bromocriptine (BRO) to suppress the peripartum PRL pulse results in a complete failure of milk production and the subsequent death of the neonates (Buttle et al. 1979, Fletcher et al. 1990). One of the possible mechanisms of this crucial PRL effect is the well-documented dependence of cyclin D1 synthesis in the mammary gland on PRL (Brockman et al. 2002). Cyclin D1 is part of a family of proteins called cyclins which together with cyclin-dependent kinases regulate cell cycle progression (Sherr 1994). Specifically, cyclin D1 plays a critical role in the proliferation of mammary epithelium during late pregnancy (Sicinski \& Weinberg 1997). In relation to TH, cyclin D1 is a potent co-repressor for TH receptors (TR) in several organs and models. Thus, cyclin D1 may act at the mammary gland epithelium as a promoter of alveolar epithelium growth and at the same time lessen the effect of TH via a limited TR response. Moreover, it is well known that hyperthyroidism suppresses PRL-mediated mammary growth in virgin rats (Mitra 1975), and the induction of hyperthyroidism during late pregnancy blocks lactation after delivery (Varas et al. 2002). Although the physiological role of TH in this period is not clear, it is suggested that an excess of TH may induce a premature involution of the alveolar epithelium (Varas et al. 2002). The present experiments were designed to analyze the interaction of PRL pulse, cyclin D1 and TH components in the peripartum period.

\section{Materials and Methods}

\section{Reagents}

Thyronines were obtained from Henning Co. (Berlin, Germany). ${ }^{125}$ I-reverse $\mathrm{T} 3 \quad(\mathrm{rT} 3 ; 1174 \mu \mathrm{Ci} / \mu \mathrm{g})$ and ${ }^{125} \mathrm{I}-\mathrm{T} 3 \quad(1200 \mu \mathrm{Ci} / \mu \mathrm{g})$ were purchased from New England Nuclear (Boston, MA, USA). Dithiothreitol (DTT) was obtained from Calbiochem (La Jolla, CA, USA), norepinephrine (NE) from Sigma Chemical Co. (St Louis, MO, USA) and BRO from Sandoz (Sandoz de Mexico, Mexico DF). Oligonucleotides were synthesized by GIBCO-BRL (Gaithersburg, MD, USA). All other reagents were of the highest purity commercially available.

\section{Animals}

The study was conducted on Sprague-Dawley primiparous rats during the periods of pregnancy and lactation. Each mother was individually housed in automatically controlled environmental conditions $\left(21 \pm 1^{\circ} \mathrm{C} ; 12 \mathrm{~h}\right.$ light: $12 \mathrm{~h}$ darkness cycle) and provided with rat Purina chow and tap water ad libitum. All animals were handled according to the International Regulations of Laboratory Animal Care. Mothers were killed by decapitation; blood and abdominal mammary glands of each individual were obtained, and the tissues were immediately frozen on dry ice.

$m R N A$ for Dio1, TRs, Spot 14 (S14) and cyclin D1

These were identified using a previously standardized semi-quantitative PCR procedure in which an amplicon of the structural protein cyclophilin (Cyc) was simultaneously amplified (Aceves \& Rojas-Huidobro 2001). The oligonucleotides used for each amplicon are summarized in Table 1. The resultant PCR fragments (in $b p$ ) were: 250 for Dio1, 254 for TR $\alpha 1,320$ for TR $\beta 1,451$ for 


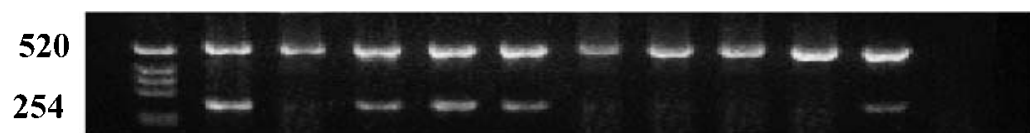

Cyc

TR- $\alpha 1$

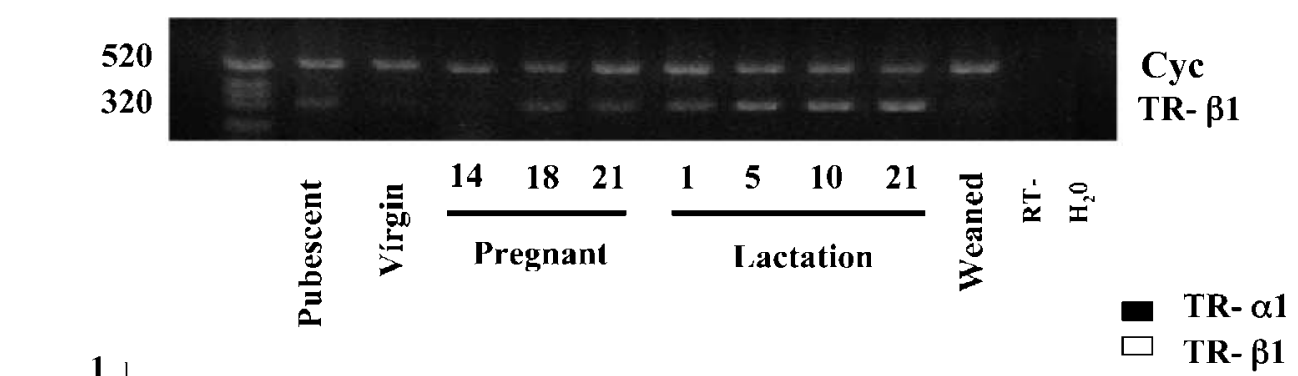

\section{Cyc TR- $\beta 1$}

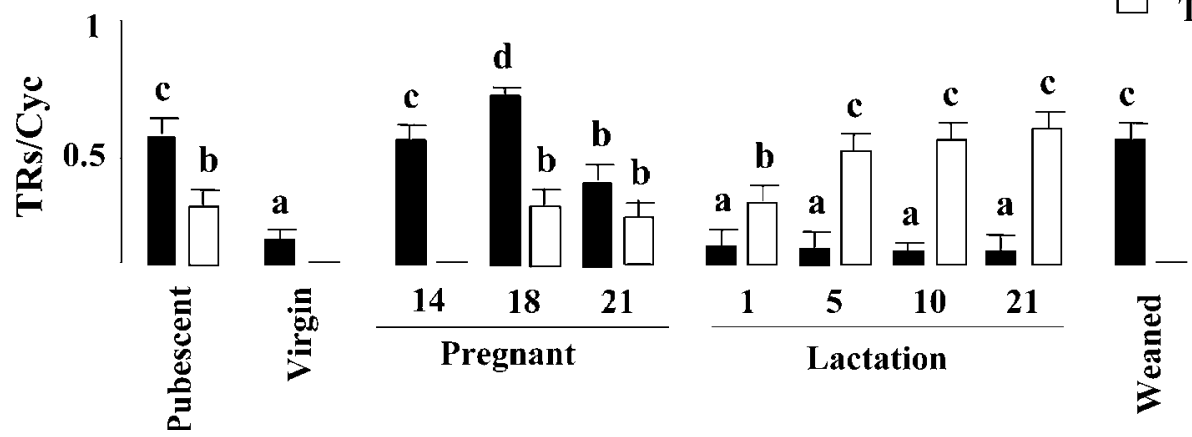

Figure 1 TRs during the breeding cycle. (Upper panel) Ethidium bromide-stained gel showing RT-PCR products for Cyc (520 bp), TR $\alpha 1$ (254 bp) and TR $\beta 1$ (320 bp) after 32 coamplification cycles. RT - , samples without reverse transcriptase; $\mathrm{H}_{2} \mathrm{O}$, water with all the PCR reagents. (Lower panel) Densitometric analysis. The experiments were repeated with three independent RNA samples and normalized to the simultaneous Cyc amplification (TRs/Cyc). Each bar represents the means \pm S.D. $(n=3) . P<0 \cdot 05$, different superscripts indicate significant differences between groups.

S14, 315 for cyclin D1 and 520 for Cyc; they were resolved on a $2 \%$ agarose gel and visualized using ethidium bromide. The sizes of the bands were confirmed by a restriction digested pUC plasmid (1 kb DNA ladder; GIBCO-BRL). A Polaroid picture was taken, the pictures were digitized using a Hewlett Packard Scanner Jet 11CX, and the signals were analyzed using an edited version of the NIH-image program (San Diego, CA, USA). Three different RNA samples from each group were analyzed.

\section{Deiodinase assay}

MDio1 activity was determined by a modification of the radiolabeled iodide release method described elsewhere and standardized for the mammary gland (Aceves \& Valverde-R 1989). Mammary glands were homogenized in $10 \mathrm{mM}$ HEPES, $\mathrm{pH} 7 \cdot 0$, containing $0.32 \mathrm{M}$ sucrose, $1.0 \mathrm{mM}$ EDTA and $10 \mathrm{mM}$ DTT, and centrifuged at $2800 \mathrm{~g}$ for $30 \mathrm{~min}$ at $4{ }^{\circ} \mathrm{C}$. Assay conditions were as follows: $200 \mu \mathrm{g}$ protein, $2 \mathrm{nM}{ }^{125} \mathrm{I}-\mathrm{rT} 3,0.5 \mu \mathrm{M}$ nonradiolabeled rT3 and $5 \mathrm{mM}$ DTT. After $3 \mathrm{~h}$ of incubation, released acid-soluble radioiodide was isolated by chromatography on Dowex 50W-X2 columns (Bio-Rad). Proteins were measured by the Bradford method (Bio-Rad). Results are expressed as pmol iodide released/mg protein per h.

\section{Cyclin D1 protein}

Cyclin D1 protein expression was analyzed by Western blot using the anti-cyclin D1 kit (MBL Laboratories, Nagoya, Japan). The protocol was carried out according to the manufacturer's manual. The immunocomplex was resolved on SDS-PAGE, transferred to a polyvinylidene difluoride membrane and immunoblotted with monoclonal antibody for cyclin D1 and horseradish peroxidase(POD) conjugated anti-mouse IgG. The membrane was exposed to an X-ray film in a dark room for $5 \mathrm{~min}$.

\section{Hormone levels}

PRL was determined with a commercial rat enzyme immunoassay kit (Amersham Biosciences). All serum samples were assayed simultaneously. Serum T3 levels were measured by the homologous RIA method previously standardized (Valverde \& Aceves 1989) with 


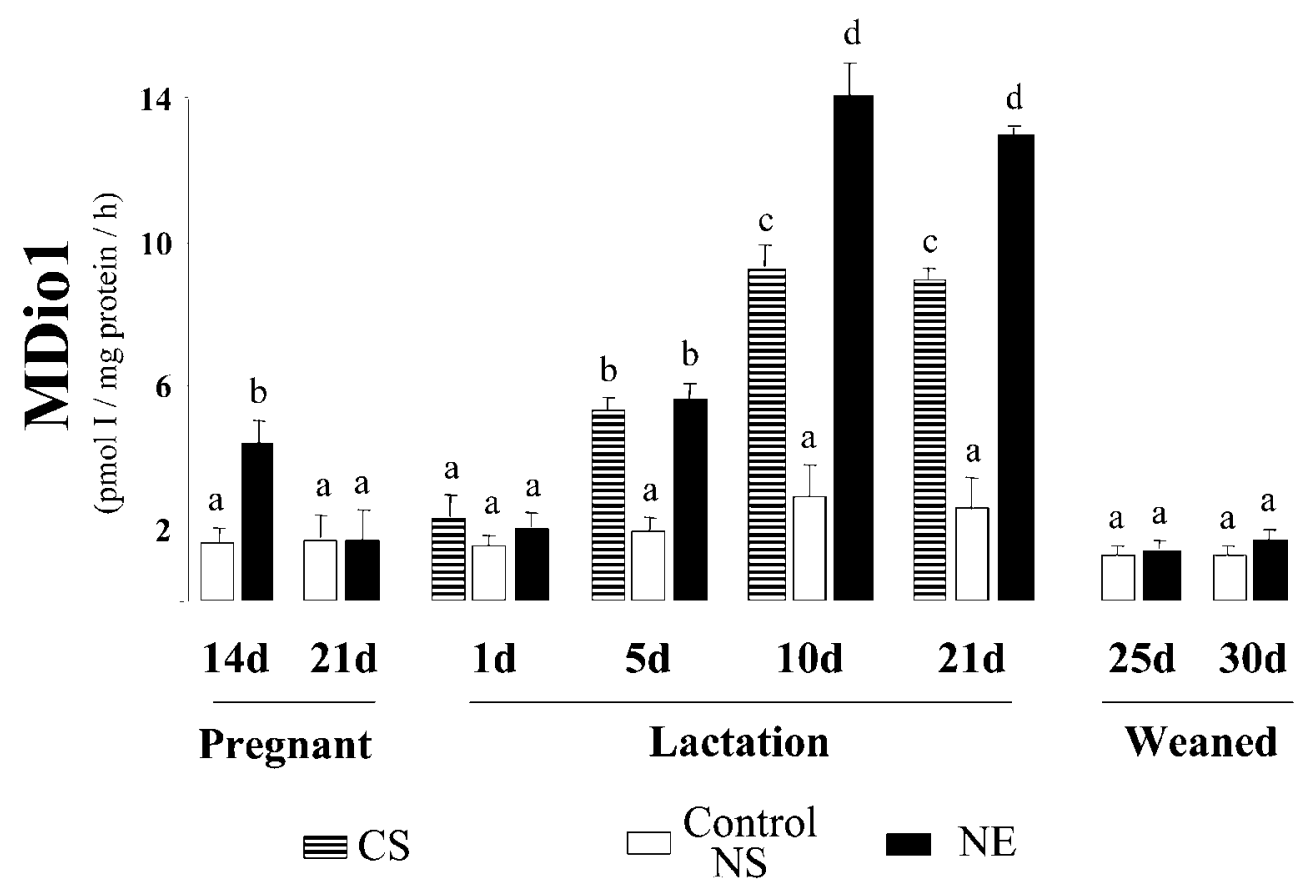

Figure 2 MDio1 activity and its response to NE during the breeding cycle (d=days). In lactating animals the litters were removed 6 or $12 \mathrm{~h}$ before NE stimulation. All animals were killed $4 \mathrm{~h}$ after the NE treatment. CS, continuous suckling; control NS, control pregnant animals, 6 or $12 \mathrm{~h}$ non-suckling lactating rats or weaned animals; NE, 6 or $12 \mathrm{~h}$ non-suckling animals or control animals which received a single NE dose. Bars represent the means \pm S.D. $(n=6) . P<0 \cdot 05$, different superscripts indicate significant differences between groups.

intra- and interassay variation coefficients of $9 \%$ and $12 \cdot 8 \%$ respectively.

\section{Statistical analysis}

Data are expressed as the means \pm S.D. Differences between experimental groups were analyzed using a twoway ANOVA and Tukey's HSD tests. Differences with a $P<0.05$ were considered statistically significant.

\section{Experimental procedures}

Expression of TRs during the breeding cycle in the mammary gland Pubescent (5 weeks), virgin (7 weeks), pregnant (days 14, 18 and 21), lactating (days 1, 5, 10 and 21) and weaned rats ( 3 days after the pups were removed) were used to analyze the mRNA expression for TR $\alpha 1$ and TR $\beta 1$ in the mammary gland.

Effect of NE on MDio1 activity In the period including pregnancy and prepartum, a single NE dose $(40 \mu \mathrm{g})$ was injected i.p. In the immediate postpartum period (6 and $12 \mathrm{~h}$ ), litters were separated from their mothers after delivery and an NE injection was given after 6 or $12 \mathrm{~h}$ without suckling respectively. In the subsequent lactation period (24 h and days 5 and 10), litters were separated from their mothers $12 \mathrm{~h}$ before the NE injection. In all cases, a single NE dose was injected i.p. and blood and mammary glands were obtained $4 \mathrm{~h}$ later. NE was dissolved in acidified saline $(900 \mu \mathrm{l}$ saline and $10 \mu \mathrm{l} 0 \cdot 1 \mathrm{M}$ $\mathrm{HCl})$. As a control, similar mothers were given a single injection of acidified saline solution.

Effect of blocking the PRL pulse on NE stimulation of MDio1, TRs, S14 and cyclin D1 during the peripartum period On pregnancy days 18 and 21, as well as at 6,12 and $24 \mathrm{~h}$ postpartum with and without suckling, and $1 \mathrm{~h}$ before the NE injection, animals received a single dose of the dopamine agonist BRO $(2.5 \mathrm{mg}$, i.p.). Four hours later, animals were killed and mammary glands were dissected. BRO was dissolved in ethanol, and the final solution was diluted with saline and adjusted to $\mathrm{pH} 7 \cdot 4$. As a control, similar mothers were given a single injection of saline solution with ethanol. All solutions were freshly prepared on the day of the experiment. All treatments were administered in the morning (0900-1200 h). S14 is a very sensitive T3-responsible gene, which we measured as a target of $\mathrm{TH}$ generation (deiodination) or TR response. 

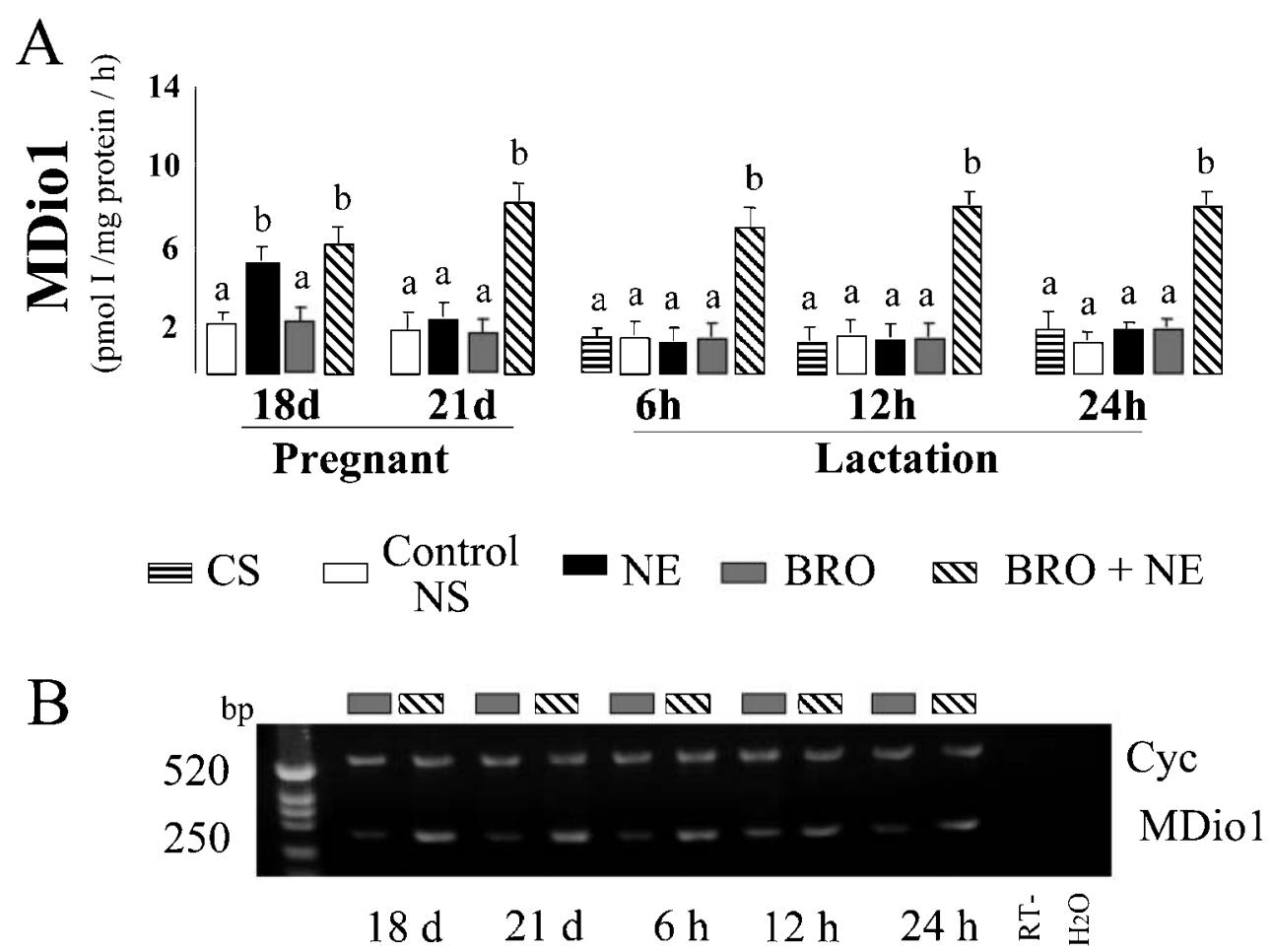

Figure 3 Effect of NE and PRL blockade (BRO) on MDio1 during the peripartum period. (A) MDio1 activity. CS, continuous suckling lactating animals; control NS, control pregnant animals or 6 or $12 \mathrm{~h}$ non-suckling lactating animals; $\mathrm{NE}$, pregnant animals or 6 or $12 \mathrm{~h}$ non-suckling lactating rats which received a single NE dose; $\mathrm{BRO}$, animals which received a single dose of $\mathrm{BRO}$; $\mathrm{BRO}+\mathrm{NE}$, animals which received one dose of BRO $1 \mathrm{~h}$ before the treatment with NE. Bars represent the means \pm S.D. $(n=6)$. $P<0 \cdot 05$, different superscripts indicate significant differences between groups. (B) Ethidium bromide-stained gel showing RT-PCR products for Cyc (520 bp) and MDio1 (250 bp) after 32 coamplification cycles. $\mathrm{RT}-$, samples without reverse transcriptase; $\mathrm{H}_{2} \mathrm{O}$, water with all the PCR reagents. The experiments were repeated twice with independent RNA samples.

\section{Results}

We have previously demonstrated that suckling is essential to maintain MDio1 levels during lactation and that adrenergic innervation is the direct activator (Aceves et al. 1999b). In the present work we used the same approach to analyze the regulation of MDio1 and other thyroid components during the pregnancy and peripartum periods. Peripartum is defined as the time between the preparation and initiation of delivery until the beginning of lactation. This period is characterized by changes in several maternal hormone levels (corticoids, growth hormone, estrogens, PRL, etc), and in the present work we considered this period between pregnancy day 21 and $24 \mathrm{~h}$ postpartum. Figure 1 shows the TR expression at different physiological stages. The highest levels of TR $\alpha 1$ expression were observed in the pubescent, pregnancy and weaning periods. In contrast, TR $\beta 1$ was mainly expressed in lactation. During the peripartum period both types of receptors expressed their lowest values.

Figure 2 summarizes MDio1 response after a single NE dose during pregnancy and lactation. It was evident that
MDio1 activity is present and NE responsive beginning on pregnancy day 14. However, in the peripartum period, MDio1 became refractory to NE stimulation. By postpartum day 5, MDio1 activity had increased in suckled rats, and it was no longer refractory to NE stimulation; these effects were more pronounced on postpartum day 10 and this response was preserved while lactation was maintained (lactation day 21). After weaning, the lack of a suckling stimulus was accompanied by significant decreases in MDio1 expression and NE response. A direct correlation between MDio1 expression and TR $\beta 1$ content was evident in pregnancy and lactation.

To analyze the interrelation between PRL and thyroid metabolism, in a second set of experiments we blocked the PRL pulse with the dopamine agonist BRO $1 \mathrm{~h}$ before NE stimulation. Our data showed that PRL blockade did not modify MDio1 basal levels. However, the injection of NE in this group raised both MDio1 mRNA content and activity as measured $4 \mathrm{~h}$ later (Fig. 3), indicating that the stimulatory effect of NE is archived at the transcriptional level and that its effect is exerted only in the absence of PRL. To corroborate that changes in mammary Dio1 

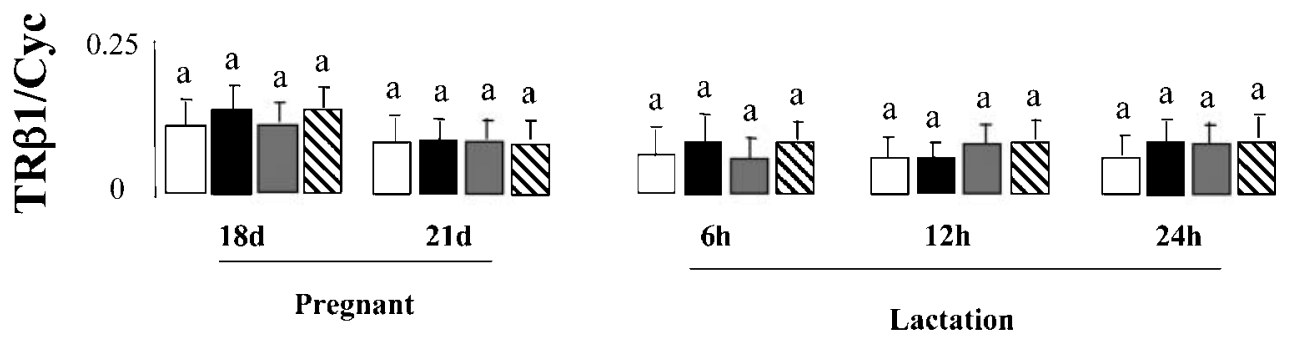

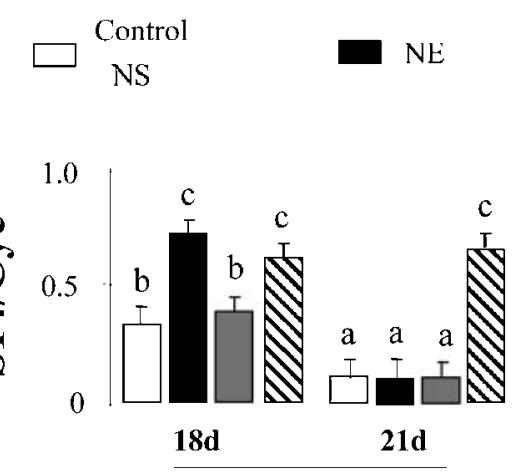

Pregnant $\square$ BRO $\quad \mathrm{BRO}+\mathrm{NE}$

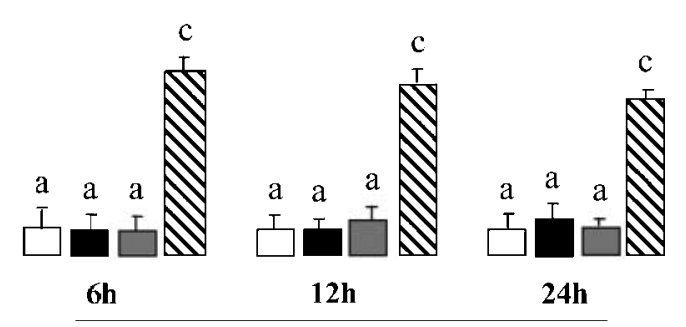

Lactation

Figure 4 Effect of NE and PRL blockade (BRO) on TR $\beta 1$ and S14 during the peripartum period. Control NS, control pregnant animals or 6 or $12 \mathrm{~h}$ non-suckling lactating animals; NE, pregnant animals or 6 or $12 \mathrm{~h}$ non-suckling lactating rats after receiving a single NE dose; $\mathrm{BRO}$, animals which received a single dose of $\mathrm{BRO}$; $\mathrm{BRO}+\mathrm{NE}$, animals which received one dose of $\mathrm{BRO} 1 \mathrm{~h}$ before the treatment with $\mathrm{NE}$; densitometric analysis. The experiments were repeated with three independent RNA samples and normalized to the simultaneous Cyc amplification (TR $\beta 1 /$ Cyc or S14/Cyc). Each bar represents the means \pm S.D. $(n=3) . P<0 \cdot 05$, different superscripts indicate significant differences between groups.

expression impact upon mammary metabolism, we analyzed TR $\beta 1$ mRNA levels on pregnancy days 18 and 6 and 24 h postpartum, as well as the expression of protein S14 which is a well-characterized T3-responsive gene. We found that TRs levels did not change in any of the treatments, and that S14 increased significantly in 18 pregnant animals treated with $\mathrm{NE}$, as well as in peripartum animals treated with $\mathrm{BRO}+\mathrm{NE}$ (Fig. 4), indicating a direct and significant correlation between local T3 generation (MDio1) and specific thyroid effect (S14). Figure 5 shows that PRL circulating levels increased significantly and sustainably within the postpartum period in continuous suckling, and 6,12 and 24 h non-suckling mothers. Data also showed that BRO administration significantly depressed PRL secretion; NE administration had no effect in any of the treatments. Figure 6 shows mammary cyclin D1 mRNA expression and protein content for this same period. This protein showed the same pattern of prolactin circulating levels. Figure 7 shows that circulating T3 levels decreased during the peripartum period. T3 levels decreased after pregnancy day 18 and were even lower at 6,12 and $24 \mathrm{~h}$ postpartum. Animals treated with $\mathrm{BRO}$ and $\mathrm{NE}+\mathrm{BRO}$ did not show any changes in circulating T3 levels, suggesting that T3- associated changes in mammary gland metabolism are exerted in an organ-specific manner.

\section{Discussion}

The present work has demonstrated for the first time that the mammary gland expresses two different types of TRs during the breeding cycle. TR $\alpha 1$ is expressed during the pubescent, pregnancy and weaning periods; whereas TR $\beta 1$ is primarily expressed during lactation. These findings coincide with a previous work showing that the mammary gland exhibits two different types of nuclear binding proteins in pregnancy and lactation (Bhattacharya \& Vonderhaar 1977), and agree with the notion that TR $\alpha$ is associated with cell differentiation or apoptosis effects; whereas TR $\beta 1$ is associated with TH metabolic regulatory functions (Brent 2000, Yen 2001). We found a close correlation between TR $\beta 1$ expression and Dio1 activity. The expression of both Dio1 and TR $\beta 1$ is discrete during pregnancy but increases significantly during the lactation period, characterized by an elevated energetic expenditure for milk production. These results are in accordance with previous reports showing this correlation between TR $\beta 1$ 

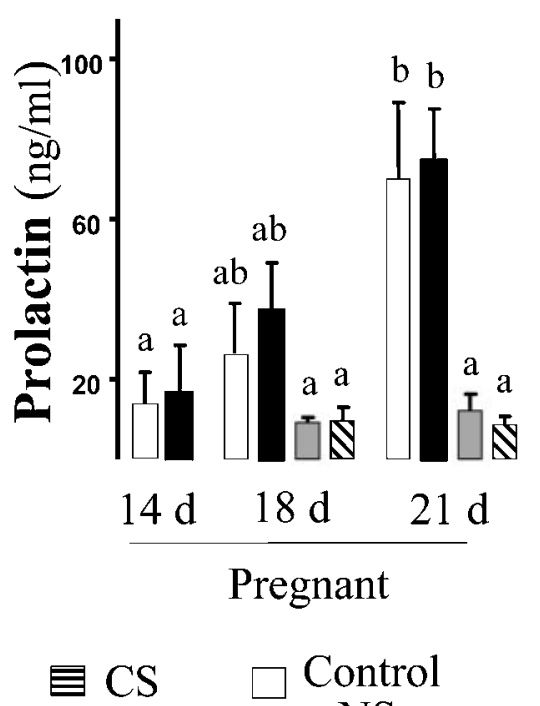

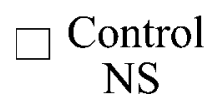

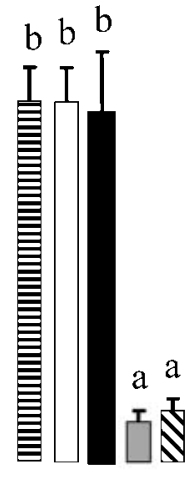

$6 \mathrm{~h}$

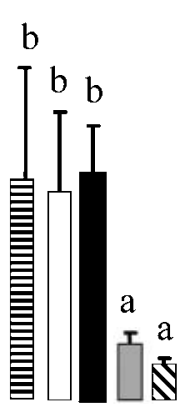

$12 \mathrm{~h}$

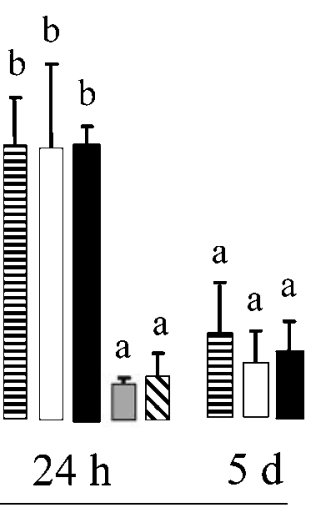

Lactation

Figure 5 Circulating levels of PRL during the peripartum period. CS, continuous suckling lactating animals; control NS, control pregnant animals or 6 or $12 \mathrm{~h}$ non-suckling lactating animals; NE, pregnant animals or 6 or 12 non-suckling lactating rats which received a single NE dose; BRO, control animals or 6 or 12 non-suckling lactating rats after receiving a single dose of $\mathrm{BRO}$; $\mathrm{BRO}+\mathrm{NE}$, animals which received a single BRO dose $1 \mathrm{~h}$ before the treatment with NE. Bars represent the means \pm S.D. $(n=6)$. P<0.05, different superscripts indicate significant differences between groups.

and Dio1 activity in other tissues with high metabolic activity, such as liver or kidney (Amma et al. 2001).

In relation to the peripartum period, the present work has confirmed and extended previous data showing that a transient and physiological hypothyroidism occurs during this stage in the mother (Calvo et al. 1990). It has also demonstrate that this hypothyroidism is regulated, at least at the mammary gland level, by the PRL pulse. Our data have shown that the mammary gland can express an NE-responsive Dio1 enzyme beginning in mid-pregnancy and continuing through lactation. However, during peripartum, both TRs and MDio1 decreased and the latter became refractory to NE, suggesting the installation of a local protective mechanism similar to the one reported for fetal brain which protects it from T3 overexposure (Calvo et al. 1990). This notion was reinforced by the finding in this study that S14 is highly expressed on pregnancy day 18 and almost disappears at the peripartum period. Peripartum has been considered a crucial period for final mammary gland differentiation and the initiation of lactation. During this period the alveolar epithelium exhibits major ultrastructural, histological (Jarmer 1977) and metabolic changes (Akers 1985). It is well documented that the induction of hyperthyroidism during late pregnancy blocks lactation after delivery. Although the physiological role of THs in this period is not clear, it has been suggested that an excess of TH may induce a precocious differentiation and/or involution of the premature alveolar epithelium (Varas et al. 2002). It is also known that hyperthyroidism eliminates the PRL pulse by suppressing thyrotropinreleasing hormone (TRH) synthesis, which is an important agonist of pituitary PRL release in late pregnancy (Van Haasteren et al. 1996, Varas et al. 2002). Although several hormones are involved in 'triggering' lactogenesis (i.e. PRL, corticosteroids and estrogen), only the suppression of the PRL pulse is followed by a complete failure to begin milk production (Buttle et al. 1979, Fletcher et al. 1990). It is possible that regulation of cyclin D1 synthesis may be crucial for this effect since this protein is a critical component of the core cell cycle machinery. Mice lacking cyclin D1 develop mammary glands that fail to undergo normal lobulo-alveolar proliferation during late pregnancy (Wang et al. 1994, Sicinski \& Weinberg 1997).

The antagonism between TH and PRL has been extensively described in many vertebrates (Tata et al. 1991, Rosato et al. 1998). In general terms, it is accepted that TH antagonizes PRL action by inhibiting Stat 5 synthesis, which is an essential element of the PRL pathway (FavreYoung et al. 2000), but the inhibitory effect of PRL upon TH is less clear. In amphibians the administration of PRL decreases T3-induced morphogenesis and tail involution (Tata et al. 1991, Tata 1999). Although the detailed mechanism has not been elucidated, it has been recently documented that cyclin D1, whose synthesis in the mammary gland is PRL dependent, is a potent co-repressor for TRs in several organs and models. This protein acts by repressing both the silencing activity of unliganded TR and the transcriptional activity of liganded TR. 


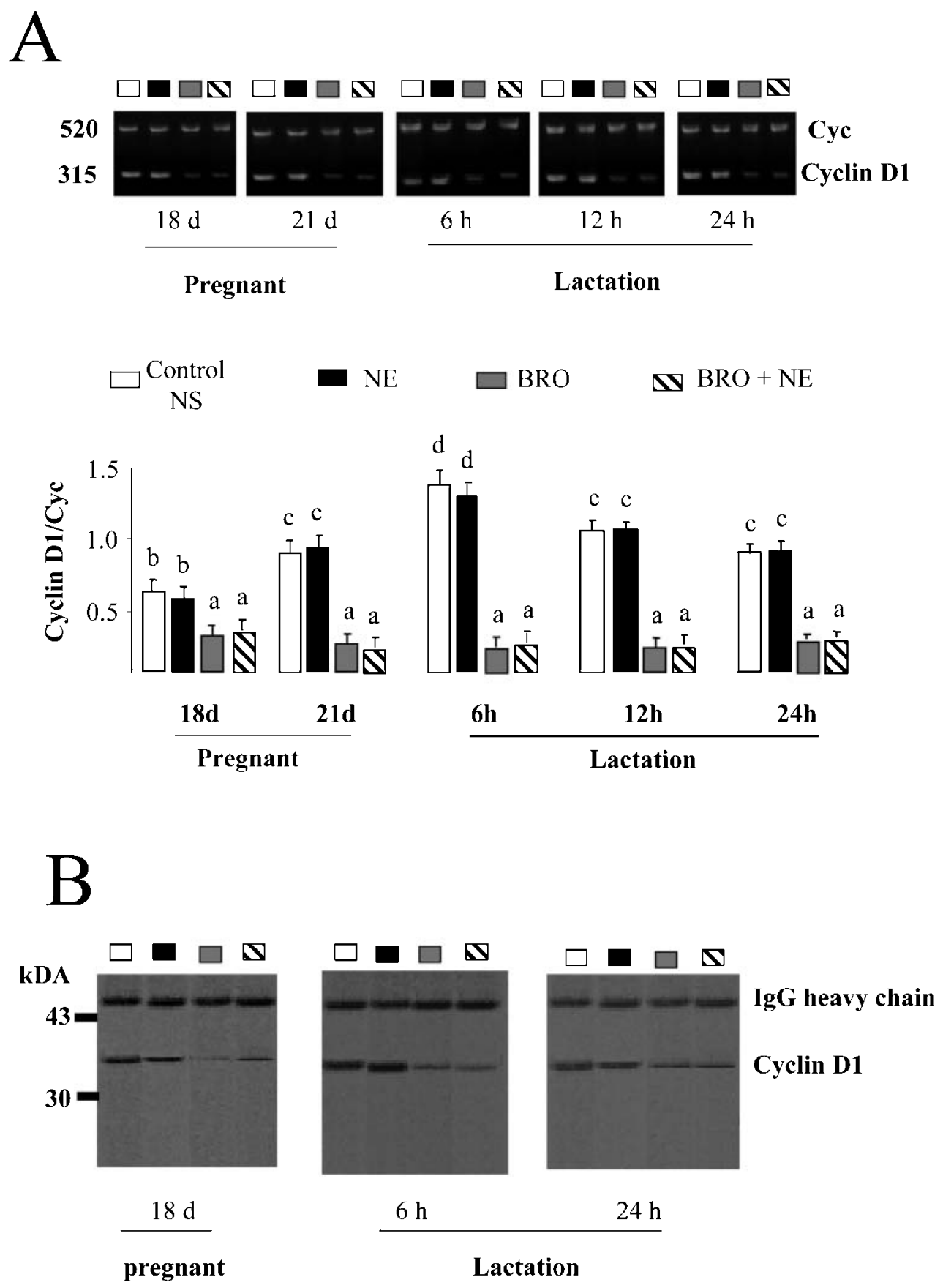

Figure 6 Effect of PRL blockade (BRO) and BRO plus NE stimulation (BRO+NE) on cyclin D1 expression during the peripartum period. (A, upper panel) Ethidium bromide-stained gel showing RT-PCR products for Cyc (520 bp) and cyclin D1 (315 bp) after 28 coamplification cycles. RT - , samples without reverse transcriptase; $\mathrm{H}_{2} \mathrm{O}$, water with all the PCR reagents. (Lower panel) Densitometric analysis. The experiments were repeated with three independent RNA samples and normalized to the simultaneous Cyc amplification (Cyclin D1/Cyc). Each bar represents the means \pm S.D. $(n=3)$. P<0.05, different superscripts indicate significant differences between groups. (B) Western blot analysis of cyclin D1 protein. A representative blot of two different assays is shown. The molecular weight of cyclin D1 was found to be $36 \mathrm{kDa}$. 

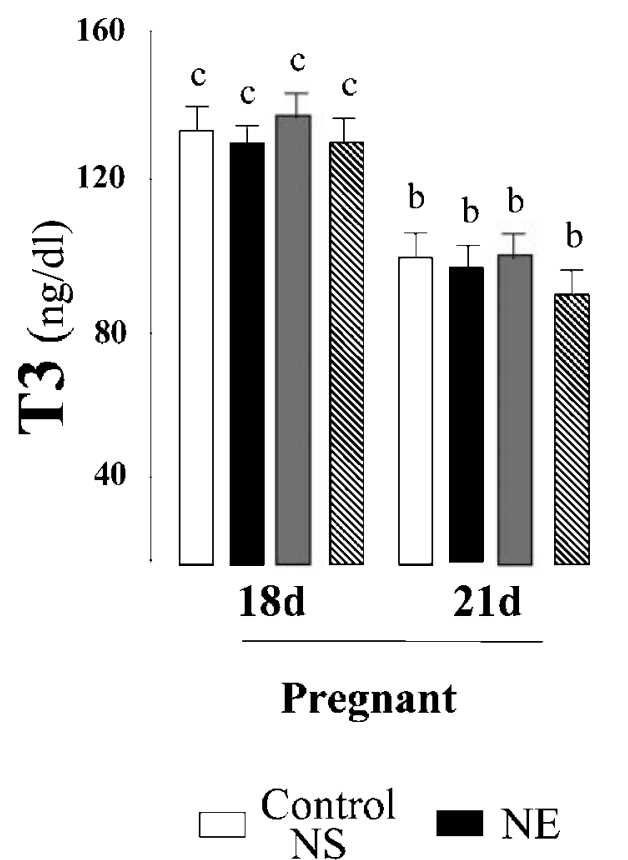

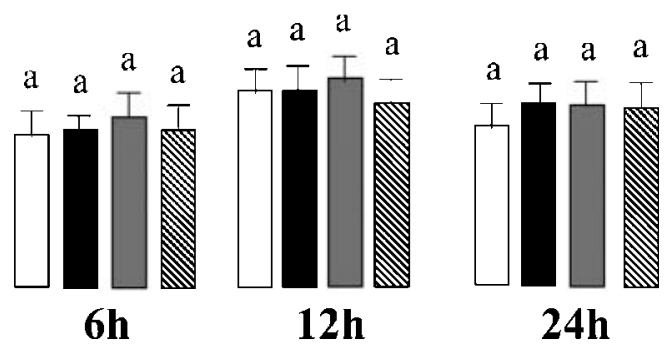

Lactation

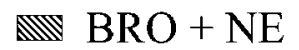

Figure 7 Circulating levels of T3 during the peripartum period. Control NS, control pregnant animals or $12 \mathrm{~h}$ non-suckling lactating rats; $\mathrm{NE}$, pregnant animals or $12 \mathrm{~h}$ non-suckling lactating rats which received a single NE dose; $\mathrm{BRO}$, animals which received a single dose of $\mathrm{BRO}$; $\mathrm{BRO}+\mathrm{NE}$, animals which received a single BRO dose $1 \mathrm{~h}$ before the treatment with NE. Bars represent the means \pm S.D. $(n=6) . P<0 \cdot 05$, different superscripts indicate significant differences between groups.

The repression is not due to the inhibition of the binding of TR to the TH response element but by serving as a bridging factor to recruit histone deacetylase 3 (HDAC3), with the resulting diminution in TR response (Lin et al. 2002). Moreover, in the mammary gland and during mid-lactation, we have demonstrated that PRL exerts a negative modulatory influence upon the $\beta$-adrenergic stimulation of MDio1. BRO administration $1 \mathrm{~h}$ before NE stimulation increases Dio1 activity by twofold, whereas the simultaneous administration of PRL and NE decreases MDio1 activity by $50 \%$ compared with NE alone (Aceves et al. 1999a). The present data support this modulatory effect of PRL upon NE stimulation, since the administration of BRO alone caused no change in MDio1 activity or S14 expression. Although further analysis is necessary to determine the exact mechanism of PRL action on MDio1, there is evidence that PRL submodulates the sympathetic activity of different brain areas influencing $\beta$-adrenergic receptor sensitivity (Dutt et al. 1994, Morales \& Mena 1995). Moreover, this modulation is consistent with the proposal that the inter-relationship of catecholamines (CAT) with PRL is the principal regulator of the length of the lactating period. This proposal considers PRL to be a promoter of alveolar growth and milk production; whereas, depending on the time during the lactating period, CAT may play either a stimulatory or an inhibitory role (Mena et al. 1991). Thus, in the peripartum period the high and sustained levels of PRL/ cylcin D1 stimulate growth and differentiation of the lobulo-alveolar complex. During mid-lactation the balance between PRL/cyclin D1 and CAT/TH maintains milk production in a mature alveolar epithelium by supporting the metabolic expenditure required for milk production. In late lactation the increasingly inhibitory influences of CAT/TH decrease PRL availability by vasoconstriction or TRH inhibition, and also increase local MDio1 activity inducing cell involution mechanisms that terminate lactation.

Finally, our data have shown that neither NE nor BRO treatment modifies TR $\beta 1$ mRNA content. This unexpected data may be explained in part by the timecourse of the experiments. Our treatments with NE and/or BRO were made with an interval of 4-6 h, which is adequate to exert the first set of effects, e.g. decrease in PRL pulse, decrease in cyclin D1 expression or increase in Dio1 expression, but not enough to visualize the secondary consequences comprising the decrease in T3 mammary content by the fall in MDio1, and the subsequent drop in TR $\beta 1$ expression. It is well documented that changes in TRs induced by T3 either in vitro or in vivo require more than $12 \mathrm{~h}$ (Strait et al. 1990). A second possibility is the modulation of the TR response by cyclin D1. The inclusion in this study of S14 led us to corroborate the idea that, during the peripartum period, the effect of 
TH upon mammary gland is a blockade. This reinforces our notion that the PRL pulse exerts its inhibitory effect at two different levels: by decreasing Dio1 NE responsiveness and, through cyclin D1, by diminishing TR response.

In summary, the present work has demonstrated that peripartum hypothyroidism is regulated, at least at the mammary gland level, by the PRL pulse and may represent a local protective mechanism shielding the immature alveolar epithelium from a T3 overexposure that would cause its premature differentiation and/or involution.

\section{Acknowledgements}

The authors are grateful to Pilar Galarza for bibliography support and Felipe Ortiz and Martín García-Servín for animal care. We also thank Lourdes Lara and Leopoldo González for image advice and Dr Dorothy Pless and Marcela Sánchez for correction of the English manuscript. This work was partially supported by grants UNAM/DGAPA IN227999 and IN224602 PAPIIT, and UC-MEXUS CN-02-98. The authors declare that there is no conflict of interest that would prejudice the impartiality of this scientific work.

\section{References}

Aceves C \& Valverde-R C 1989 Type I 5' monodeiodinase activity in lactating mammary gland. Endocrinology 124 2818-2820.

Aceves C \& Rojas-Huidobro R 2001 Effect of sucking and sympathetic nervous system on peripheral deiodination in the lactating rat. Journal of Endocrinology 171 533-540.

Aceves C, Rodón C, Ramírez-C I, Wilson S, Pineda O, López-B L, Mancilla R \& Valverde-R C 1995 Mammary 5'deiodinase (5’D) during the breeding cycle of the rat: indirect evidence that $5^{\prime} \mathrm{D}$ type I is specific to the alveolar epithelium. Endocrine 3 95-99.

Aceves C, Pineda O, Ramírez-C I, de la Luz Navarro M \& Valverde-R C 1999a Mammary type I deiodinase is dependent on the suckling stimulus. Differential role of norepinephrine and prolactin. Endocrinology 140 2948-2950.

Aceves C, Rojas-Huidobro R, Marina N, Morales MT \& Mena F $1999 b$ Mammary gland sympathetic innervation is a major component on type I deiodinase regulation. Endocrine 11 115-121.

Akers RM 1985 Lactogenic hormones: binding sites, mammary growth, secretory cell differentiation, and milk biosynthesis in ruminants. Journal of Dairy Science 68 501-509.

Akers RM, Bauman DE, Capuco AV, Goodman GT \& Tucker HA 1981 Prolactin regulation of milk secretion and biochemical differentiation of mammary epithelial cells in periparturient cows. Endocrinology 109 23-30.

Amma LL, Campos-Barrios A, Wang Z, Vennstrom B \& Forrest D 2001 Distinct tissue-specific roles for thyroid hormone receptors $\beta$ and $\alpha 1$ in regulation of type 1 deiodinase expression. Molecular Endocrinology 15 467-475.

Anderson GW, Mariash CN \& Opperheimer JH 2000 Thyroid hormone action. In Werner and Ingbar's The Thyroid. A Fundamental and Clinical Text, pp 174-195. Eds LE Braverman \& RD Utiger. Philadelphia, USA: Lippincott-Raven.

Bhattacharya A \& Vonderhaar BK 1977 Specific binding proteins for 3,5,3'-triiodothyronine in mouse mammary epithelium. 70th Annual Meeting of the American Society for Cell, San Diego, CA, 1977, Abstract CD895.
Brent GA 2000 Tissue-specific actions of thyroid hormone: Insights from animal models. Reviews in Endocrine Metabolism and Disorders 1 $27-33$.

Brockman JL, Schroeder MD \& Schuler LA 2002 PRL activates the cyclin D1 promoter via the JaK2/Stat pathway. Molecular Endocrinology 16 774-784.

Buttle HL, Cowie AT, Jones EA \& Turvey A 1979 Mammary growth during pregnancy in hypophysectomized or bromocriptine-treated goats. Journal of Endocrinology 80 343-351.

Calvo R, Obregon MJ, Ruiz de Ona C, Ferreiro B, Escobar Del Rey E \& Morreale de Escobar G 1990 Thyroid hormone economy in pregnant rats near term: a 'physiological' animal model of nonthyroidal illness? Endocrinology 127 10-16.

Dutt A, Kaplitt MG, Kow LM \& Pfaff DW 1994 Prolactin, central nervous system and behavior: a critical review. Neuroendocrinology 59 413-419.

Favre-Young H, Dif F, Roussille BA, Demeneix PA, Kelly PA, Edery M \& de Luze A 2000 Cross-talk between signal transducer and activator of transcription (Stat5) and thyroid hormone receptor-B1 (TRB1) signaling pathways. Molecular Endocrinology 14 1411-1424.

Fletcher TP, Shaw G \& Renfree MB 1990 Effects of bromocriptine at parturition in the Tammar wallaby, Macropus engenii. Reproduction, Fertility and Development 2 79-88.

Jarmer S 1977 Histology of induced bovine lactogenesis. Journal of Dairy Science 58 853-860.

Lin H, Zhao L \& Cheng S 2002 Cyclin D1 is a ligand-independent co-repressor for thyroid hormone receptors. Journal of Biological Chemistry 277 28733-28741.

Mayollan A \& Horowitz M $2002 \beta$-adrenergic signaling and thyroid hormones affect HSP72 expression during heat acclimatizing. Journal of Applied Physiology 93 107-115.

Mena F, Clapp C, Aguayo D, Morales MT \& Martínez de la Escalera G 1991 Stimulatory and inhibitory effects of suckling on lactation. Endocrine Regulations 25 25-35.

Mitra I 1975 Potency of thyroid hormone analogues in suppressing prolactin-mediated mammary growth in thyroidectomized rats. Experientia 31 1218-1219.

Morales MT \& Mena F 1995 Effects of centrally administered prolactin upon mammary contractility in anesthetized lactating rats. Neuroendocrinology 62 207-214.

Rosato RR, Jammes H \& Jahn GA 1998 Effect of chronic thyroxine treatment on pregnancy in rats: effects on oestrogen, progesterone, prolactin and GH receptors in uterus, liver and mammary gland. Endocrine Research 24 269-284.

Schams D, Reinhardt V \& Karg H 1972 Effect of 2-bromo-ergocryptine on plasma prolactin levels during parturition and onset of lactation in cows. Experientia 28 697-699.

Sherr CJ 1994 G1 phase progression: cyclin on cue. Cell 79 551-555.

Sicinski P \& Weinberg RA 1997 A specific role of cyclin D1 in mammary gland development. Journal of Mammary Gland Biology and Neplasia 2 335-342.

Silva E \& Larsen PR 1983 Adrenergic activation of triiodothyronine production in brown adipose tissue. Nature 305 712-713.

Strait KA, Schwartz HL, Pérez-Castillo A \& Oppenheimer JH 1990 Relation of c-erbA mRNA content to tissue triiodothyronine nuclear binding capacity and function in development and adult rats. Journal of Biological Chemistry 265 10514-10521.

Tata JR 1999 Amphibian metamorphosis as a model for studying the developmental actions of thyroid hormone. Biochimie 81 359-366.

Tata JR, Kawahara A \& Baker BS 1991 Prolactin inhibits both thyroid hormone-induced morphogenesis and cell death in cultured amphibian larval tissue. Development Biology 146 72-80.

Valverde- R C \& Aceves C 1989 Circulating thyronines and peripheral monodeiodination in lactating rats. Endocrinology 124 $1340-1344$ 
Van Haasteren GA, Van Toor H \& Klootwijk W 1996 Studies on the role of TRH and corticosterone in the regulation of prolactin and thyrotropin secretion during lactation. Journal of Endocrinology 148 325-336.

Varas SM, Muñoz EM, Hapon MB, Aguilera-Merlo CI, Gimenez MS \& Jahn GA 2002 Hyperthyroidism and production of precocious involution in mammary glands of lactating rats. Reproduction 124 691-702.
Wang TC, Cardiff RD, Zukenberg L, Lees E, Arnols A \& Schmid EV 1994 Mammary hyperplasia and carcinoma in MMTV-cyclin D1 transgenic mice. Nature 369 669-671.

Yen PM 2001 Physiological and molecular basis of thyroid hormone action. Physiological Reviews 81 1097-1142.

Received 10 June 2004

Accepted 3 August 2004 